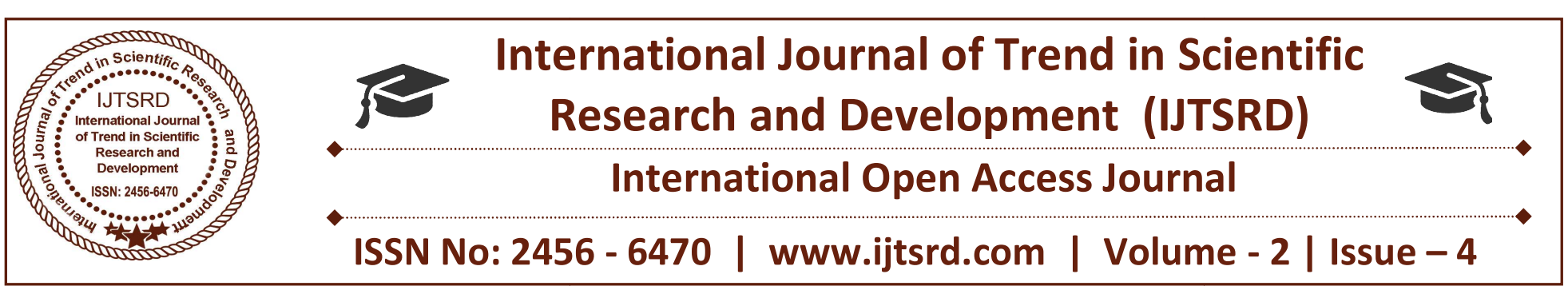

\title{
Millennials the Future Leader Bring a New Perspective to the Leadership in the Workplace and Society
}

\author{
Dr. Rajshri Randive Admane \\ Assistant Professor, Rashtrasant Tukadoji Maharaj Nagpur University, \\ Nagpur, Maharashtra, India
}

\section{ABSTRACT}

The face of leadership is changing. The future of business world is in the hands of millennials. Known for their engagement with digital technology. Millennials have been changing the workplace ever since they started arriving on the scene nearly a decade ago. The average age of people in leadership training is closer to 42 it is crucial for HR leaders to deploy strategies on how to attract and draw top millennial talents to company. Main focus of this research paper on how millennials are prepared to take on leadership roles. Also study focus on distinct characteristics and work style of the millennials. Millennials are exposed to more racial and ethnic diversity, which makes them better at working in a team across geographies rather than individually. Seeking for new challenges and flexibility at work, they tend to avoid tedious work pace that obliges them to deal with monotonous paperwork. To prepare for the big wave of upcoming millennials entering your business, this piece will provide you with sound insights on how to manage the next-generation of talented leaders. The study shows how millennials are keen on learning fast from their higher-ups, so organizations need to invest a lot of time to train, mentor and assist them in getting their jobs done. Millennials leaders should be able to socialise company's values and ask for their commitment towards achieving the organization vision. Millennials are used to working with diverse co-workers, they can work best in a team and are good at networking. Millennials leaders firmly believe that 'two is better than one', which means more can be accomplished by working in groups, rather than alone. Possessed with capabilities to create wide networks, you can take advantage of this generation's ideas to reach out to global audiences. The report synthesises review and summaries the findings of data and research literature on the subject.

Keywords: Millennials, Leaders, Workplace, Workstyle, Generation \& Values.

\section{INTRODUCTION}

Companies have a huge opportunity to get top talent because Millennials are looking for the next shiny opportunity. Born in an era where information can be accessed in matter of seconds, millennials are highlyengaged with technology and they are digital savvy. Compared to other generations, their level of technology-literacy is more than you could possibly imagine. Businesses can harness their talent potential to improve efficiencies in workings and generate positive outcomes. Millennials are kids who are born in between 1980-2000. As of the year of 2017, they are around the age of 26 . This generation is digitalsavvy, ambitious and social job seekers. According to Monster, companies might need to revisit their recruiting strategy. It has been estimated that millennials will compromise $50-75 \%$ of the job market in 10 years. Some of them are already entering the job market right now. With this huge shift of demographic, companies will need to start to adapt if they haven't. Answering phone calls when penning down emails is no big deal for millennials. They are sharp, and good at multitasking. They can perform several jobs simultaneously with unilateral focus, which is a great benefit for company's productivity. Too often, social media is underutilized as a hiring tool. Most Recruiters use LinkedIn, Twitter, Facebook, Instagram and the like only to post job 
opportunities. However, if you want to attract Millennials and other tech-savvy talent, you need to do more than that. From an HR perspective, social media is about creating an aura that you are the employer of choice. For most millennials, work has to be fun, because boring is bad. They want to have fun at work without neglecting their responsibilities. To create a happy and enjoyable atmosphere at work, HR managers should create recreation rooms where millennials can relax between tight schedules, modern cafeteria where workforce across departments can meet and gather, or hold community events for employees to develop interpersonal relationship with their co-workers. HRs should also take active interest in encouraging healthy life-work balance by investing into construction of mini sport centres or yoga rooms.

Yet having grown up with the freedom technology provides, they want a career that looks very different from their parents' and embraces that flexibility. With so many employment options available, they can be as choosy about where and how they work as they are about their food; they want to work with purpose as part of an organization whose values and culture align with their own, whether they are free-range chickens or battery hens. But unlike their older siblings, millennials won't hang around unless they have a voice, feel included, and find purpose in their work, and that often means joining an organization that stands by a strong set of values.

Organizations who have really mastered the values game have employees with a sense not only how the values support the company's reason to exist, but how its corporate values statement translates into day-today actions. A recent study by LRN demonstrated that companies with the highest levels of principled behaviour are the ones that have placed values at the centre of their organizations. By allowing the values to become a business enabler, as a reference for tough decisions, employees can find a greater personal purpose in their work, propelled beyond figures in a ledger. The leaders of such organizations can be secure in the knowledge that a values-driven enterprise is good not only for the people who work there but is at a competitive advantage in today's brand-conscious marketplace. So, it makes sense that an organization that allows its values to lead would be attractive to a millennial workforce hungry for meaning.

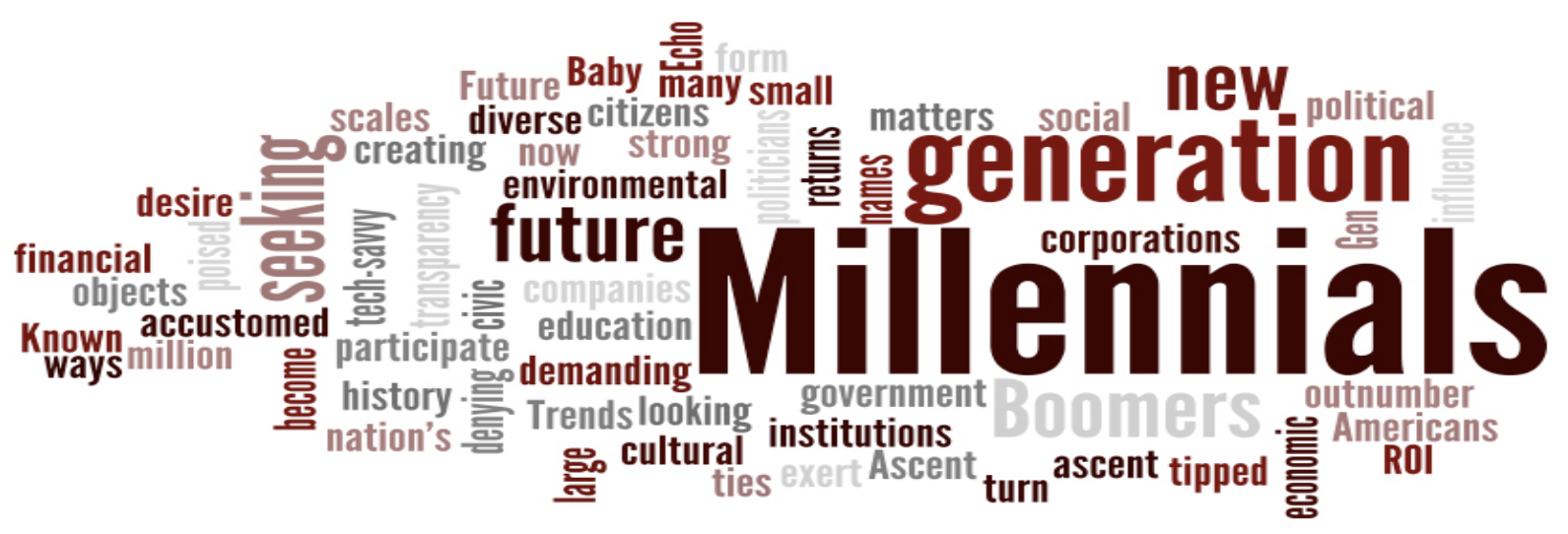

\section{REVIEW OF LITERATURE}

About the survey a study into the future of people management, 'Managing tomorrow's people - the future of work 2020', which explained how globalism, technology, and sociopolitical and demographic changes would influence the way businesses operate in the future. The follow-up report, 'millennials at work: Perspectives of a new generation', was published in 2008 and highlighted the characteristics of the newest generation of workers. This latest report aims to provide some insight into the minds of new graduates from around the world entering the workforce for the first time. CEOs are becoming increasingly concerned that they will soon be unable to find the talent that they will need to succeed, with a shortage of suitably skilled workers their single biggest worry. Businesses are competing fiercely for the best available workers and for the talent that will replace the retiring Boomer generation in the coming few years. Every year, more and more of that talent will be recruited from the 
ranks of millennials. As they begin their working lives, what are the hopes and expectations of this generation? And most importantly, do business leaders and HR teams need to revise their current strategies accordingly? PwC commissioned Opinion Research to carry out an online survey of 4,364 graduates across 75 countries between 31 August and 7 October 2011. 1,706 of these respondents were PwC graduate recruits or responded through $\mathrm{PwC}$ 's website. Overall, 1,470 PwC employees and 2,894 other graduates responded to the survey. All were aged 31 or under and had graduated between 2008 and $2011.75 \%$ are currently employed or are about to start a new job. $8 \%$ were unemployed at the time they filled in the questionnaire. The rest were self employed or returning to full-time education. $76 \%$ of those with a job said it was a graduate role, while $12 \%$ had a job which did not require a degree.

The millennial generation, born between 1980 and 2000 now entering employment in vast numbers, will shape the world of work for years to come. Attracting the best of these millennial workers is critical to the future of your business. Their career aspirations, attitudes about work, and knowledge of new technologies will define the culture of the $21 \mathrm{st}$ century workplace. Millennials matter because they are not only different from those that have gone before, they are also more numerous than any since the soon-to-retire Baby Boomer generation millennials already form $25 \%$ of the workforce in the US and account for over half of the population in India. By 2020, millennials will form $50 \%$ of the global workforce. But although they will soon outnumber their Generation $\mathrm{X}$ predecessors, they remain in short supply, particularly in parts of the world where birth rates have been lower. They will also be more valuable

A Pew Research conducted in 2015 found that one third American workers are millennials. While in Singapore, millennials make up for 22 percent of resident population, which makes them the largest market with great employment potential. According to the 2017 Deloitte Millennial survey' millennials share many of the same career goals as Generation $\mathrm{X}$ and the Baby Boomers, yet having grown up with the freedom technology provides, they want a career that looks very different from their parents' and embraces that flexibility.

\section{OBJECTIVES OF THE STUDY}

1. To find out how millennials are prepared to take on leadership roles.

2. To know how millennials are changing things

3. To study millennials distinct characteristics and workstyle

4. To analyzes the right talent and to retain people

5. To understand how social media is underutilized as a hiring tool.

6. To study how millennials have a interest in social issues, creating change in the world, being part of positive action.

\section{SCOPE OF THE STUDY}

The study is helpful to the organizations to recruit right talent like millennial. Give them a training and retain them. Because millennials are the future leaders, they believe in changing things, more and better feedback, more fluid adoption of new technology. Millennials are at the forefront of a leadership movement. Study demonstrated that companies with the highest levels of principled behaviour are the ones that have placed values at the centre of their organizations. By allowing the values to become a business enabler, as a reference for tough decisions, employees can find a greater personal purpose in their work. Millennials bring a new perspective to the very idea of leadership not just in the workplace, but also across society in general

\section{MILLENNIALS ARE PREPARED TO TAKE ON LEADERSHIP ROLES -}

5.1 Age and experience: Millennials are beginning to age, wandering into their $30 \mathrm{~s}$. With a decade or more of experience under their belts, they're ready for bigger roles.

5.2 Numbers: Millennials have officially become, and represent the largest percentage of the workforce. Because there's a growing power vacuum as managers from older generations leave or climb even higher, millennials are the most plentiful candidates to fill the void.

5.3 Autonomy and confidence: Millennials crave autonomy, and have confidence in their skills; those characteristics drive them to take charge of more people and more responsibilities. Workplace autonomy is a big job requirement for millennial workers, their relationship to their supervisors, their boss and how often can be a little complex. 


\section{HOW MILLENNIALS ARE CHANGING} THINGS :

Millennials are leading in different ways from their older generation

6.1 More and better feedback-All millennials wanted feedback regularly; they also refused to ask for it. This urge for feedback and understanding of feedback's importance will likely follow them into leadership positions, except as leaders, they'll have the power to institute a powerful system.

6.2 More fluid adoption of new technologyMillennials, who tend to be more optimistic and more adaptable when it comes to new technologies, will likely institute more advanced platforms at a faster rate than their predecessors. Millennials trust the power of technology, and know that adopting better systems is the most efficient way to make better decisions. Overarching platforms, like project portfolio management software, may become more common as millennial leaders rely on its abilities to make better decisions and organize resources.

6.3 More flexibility and fewer rule - Millennials agreed that more flexible working hours would make their generation more productive. Carrying this philosophy into a position of leadership, Millennial leaders will likely instate more flexibility, including customizable hours, more remote work, and even more relaxed rules in the office.

6.4 Higher demands for brand values and company culture - Millennial leaders could be more demanding for workers to adhere to their brand, company culture and core values. Values have always been an important cultural institution for Millennials, when choosing an employer or a supplier, and now they get to create and enforce those values within the context of their own teams.

6.5 Preparation for generation - Millennials are aging, and will likely be looking over their shoulder as the next generation usually referred to as 'generation $Z$ ' or the 'post-Millennial' generation as they start rising through the ranks themselves. Millennials will have a brief period of enjoying the energy of youth alongside the experience necessary to drive true changes in the workplace.

\subsection{Updating Recruitment Strategies}

Millennial leaders are finding that they update their recruitment strategies to successfully connect with younger workers who expect faster and more-informal communications as well as frequent feedback. What recruiters fail to grasp is that this is a generation where the accelerated speed of communications is extraordinary. It's not the old days of 'Don't call us, we'll call you. Recruiters and hiring professionals need to recognize that career choice is a two-way street, not a one-way street. And their jobs don't end when a hire is made. That means their strategies for retaining younger workers by showing them a clear career path forward for promotion. The trend is for HR to be a resource, not just a rule enforcer.

\subsection{Millennials leaders what these young people} want to know about new job opportunities.

$>$ To find out more about your organization, they are more likely than members of other generations to follow it on social media.

The most important information they want to know about your company is its culture and values.

The top obstacles to accepting a job for millennial workers are not knowing what the organization is like, applying and not hearing back, and not understanding the role.

\section{TIPS FOR MILLENNIAL RECRUITER}

\subsection{SOCIAL MEDIA TIPS}

1. Use social media to project your company's values and mission, highlight your best employees, and showcase organization-led volunteer opportunities that support the local community.

2. Be aware of what's being said about your organization on social media and respond when necessary.

3. Partner with universities, colleges, and friends and families of workers to help get the word out about your company.

4. Tie social media messaging to your organization's values, particularly if they are identified on your website. If diversity is prized, reflect that in the staff images on your social network pages.

5. Work with your public relations and marketing departments to create an appealing narrative around your organization. 
6. Encourage workers to share creative photos that align with the company's values and mission.

7. Be authentic. Don't rely exclusively on the HR and PR departments to take and post photos.

\subsection{HIGHLIGHT CULTURE AND MISSION}

Culture is a top factor when recruiting Millennials. Pay is also important, but the biggest pull for many younger workers is whether the company's culture aligns with their values. Job seekers want to know if a position will help them make an impact on their community and environment; recruiters need to keep that in mind when they're posting openings. For instance, if you're a recruiter and are hiring for a call center position, don't just include the basic requirements. Instead, explain the opportunity that the job presents and talk about the organization and its mission.candidates know what kind of place they are, and I want to know that they can assimilate into the culture and have the same mission. Millennials want to feel that the people in senior positions also believe in the mission.

They are also looking to forge a connection with the people they'll be working with. Many young people even like to think of their colleagues as family.If they are working with good friends. Even if another company wants to give them extra money, they are less likely to take the offer because they don't want to leave behind their work family.

\subsection{PROVIDE A CAREER ROAD MAP}

One of the best ways to recruit and retain younger workers in the early stages of their careers is to show them a path forward with the company. Millennials also want to know whether the organization is invested in their growth. If they can't see a path up, they will move on. They want to know that if they do A, B and C, after two to five years, they'll potentially be here and then move here. They need to understand where they fit into the future of the company and how management and HR will help them get there. Millennials show enthusiasm for management opportunities.

One of the best ways to recruit and retain younger workers in the early stages of their careers is to show them a path forward with the company.

\section{THE CHALLENGES OF RECRUITING THE NEW GENERATION: MILLENNIALS}

Here are the main characteristics of millennials and why they differ from old generations:

\section{$>$ Ambition and Values come first, money comes second.}

The millennials approach their careers differently than the older generations. Their top priority is to look for a company to foster innovation and contribution to the society instead of having a stable paycheck. To attract ad retain talent, companies need to show Millenials it is innovative and in tune with their world-view.

\section{They are learners and they want to grow.}

Millenials are aggressive ambitious individuals and they seek experience as much as possible. Employers and manager will need to understand the personal and professional goals of millennials. It is ideal to give them assignments that have a frequent rotation to give them a sense of advancement. They like to be challenged by projects that could stimulate their creativity or could encourage them to use new ways to do things. They have the tendency to work overseas because to gain better experience and advancement. This could be a good potential resource for businesses that are focusing on global growth.

\section{Millennials like to advance in a faster paste.}

Usually, career advancements are measured by seniority and time of services, but millennials don't think that way. Millenials like to work in a fast paste environment. They want advancement much quicker and they value results over security than older generations who are accustomed to. In results, at times they feel frustrated for working up the career ladder.

\section{$>$ MILLENNIALS NEED FLEXIBILITIES.}

This generation is the type who needs clear instructions and a concrete target. If you give them a deadline, what is the big deal of the process to get the task done? Or would it matter if they work in a coffee shop or somewhere else that could make them more productive? Millenials likes to complete tasks in their own way or not being micromanaged. They will deliver the job on time, and you wouldn't need to worry too much about the process. 


\section{THEY HAVE AN ENTREPRENEURIAL} SPIRIT.

The older generations were extremely monogamous about their careers. Since millennials are aggressive ambitious individuals, they are risk takers and more entrepreneurial. According to survey, $70 \%$ of the Millennials envision working for themselves at some point during their careers. Considering that the population demographic will occupy a big part of the job market, traditional companies might be threaten by this.

\section{LAST BUT NOT LEAST, BE PREPARED TO BE INTERVIEWED.}

It is fairly easy for these tech-savvy individuals to do a full research on the position, the interviewer and the company just by a few clicks on the internet or other resources. Therefore, the companies are under pressure to maintain their positive reputations and that they are able to publicly demonstrate their productive, equitable and progressive work environment. Recruiters will need to cater to this knowledge and need to expect the interview will be a two-way street. Be prepared, the wave of ambitious youth will flood the job market soon. Companies will need to start working on a plan to accommodate to these changes.

\section{FOUR HR MISTAKES MILLENNIAL} LEADERS NEED TO AVOID: Millennials make a few common workplace mistakes that if corrected, can help any millennial leaders be a better boss, and advance through the ranks more quickly. Here are 4 common HR mistakes to avoid.

\subsection{Being a friend first and a manager second}

Since Millennials tend to prefer working environments that are less hierarchical and more flat, some Millennial leaders often make the mistake of viewing colleagues as friends first. This is a miscalculation that can lead to HR issues. Some of today's most successful companies suffer from unprofessional HR habits that come about when managers think of employees as friends instead of colleagues. For example, a manager who thinks it's ok to make an off-color joke at work will end up alienating the employees he or she is charged with leading.

Successful Millennial managers understand that being friendly at work and making meaningful connections with colleagues is different than treating colleagues like friends. At the end of the day working relationships must be based on what best serves the goals and needs of the business, Millennials who understand this and who are able to manage subordinates appropriately will be more successful than those who treat colleagues like friends first.

\subsection{Only hiring candidates who share a common background}

The Kellogg School of Management at Northwestern University recently conducted a study about implicit hiring bias among hiring managers at elite companies. The study concluded that indeed hiring managers did hold implicit (meaning subconscious) biases that favored candidates who shared certain traits with the hiring manager. This not only lead to workplaces that were less diverse than they could have been, but it also caused hiring managers to overlook highly talented candidates. Despite their reputation for being more egalitarian and open minded, Millennial hiring managers are still all too likely to allow shared socioeconomic background to influence hiring decisions.n order to minimize the impact of implicit bias in hiring, consider establishing a blind panel of hiring managers who decide on each candidate's worthiness based on previous performance, and an assessment. Try to minimize information that includes socioeconomic indicators as much as possible.

\subsection{Failing to Run High Quality One-on-One Meetings}

The one-on-one meeting is the only time a manager can share and receive meaningful feedback with a subordinate in a consistent and structured way. Yet too few Millennial managers make use of one-on-one meetings. one-on-one meetings allow both the leader and the subordinate an opportunity to share candid feedback. Following feedback, there should be a system in place to ensure that any action items that arise from the meeting actually happen.

\subsection{Communicating inappropriately with a subordinate:}

Millennial managers understand that employees are colleagues first and friends second communicating inappropriately will cost companies top talent, cause PR nightmares, and worst of all, cause serious psychological harm to who are victims of inappropriate workplace communication. 


\section{I . Who Are Millennials, Their Likes and Work Jobs :}

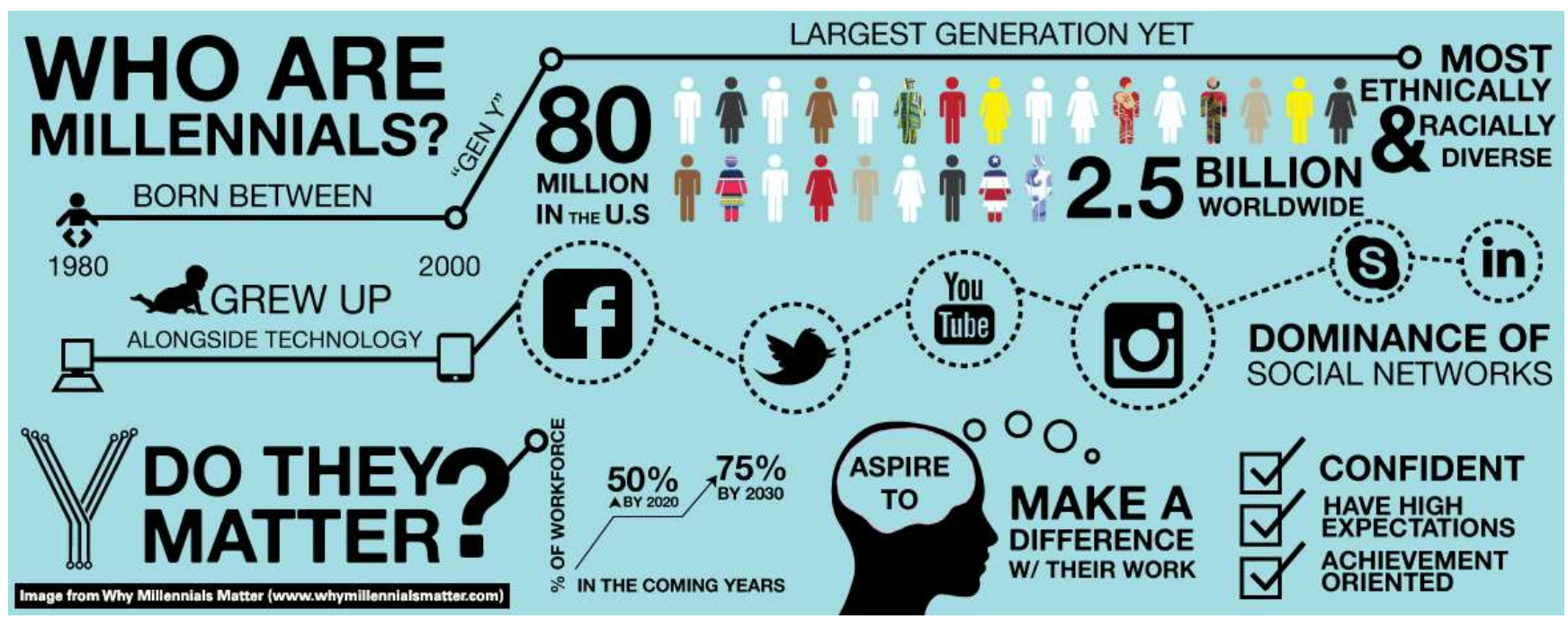

Source: Linkedin.com

\section{Image showing millennials leadership and career path.}

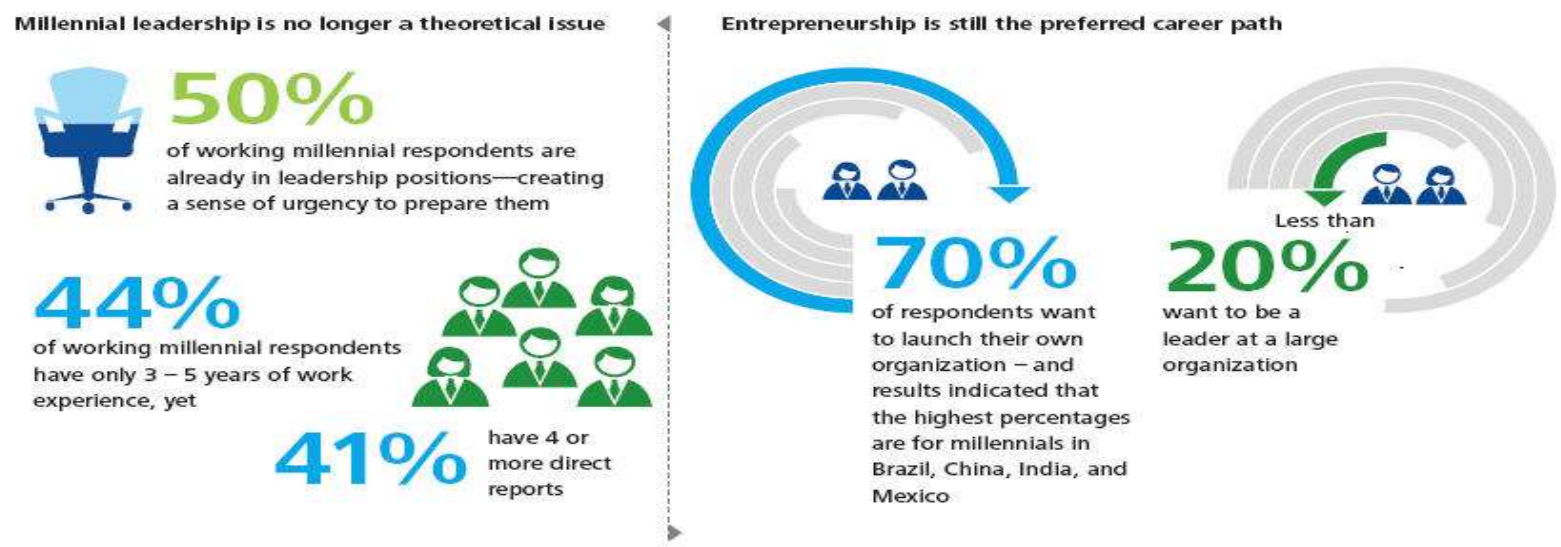

Source: weforum.org

\section{FINDINGS AND DISCUSSION OF THE}

\section{STUDY}

Millennials have a strong appetite for working overseas and $71 \%$ expect and want to do an overseas assignment during their career. This is great news for many employers looking for global growth. However, the bad news is that millennials place destinations like the US, UK and Australia at the top of their wish list, and only $11 \%$ were willing to work in India and $2 \%$ in mainland China. Despite this, over half said they would be willing to work in a less developed country to further their career.

Career progression is the top priority for millennials who expect to rise rapidly through the organization. $52 \%$ said this was the main attraction in an employer, coming ahead of competitive salaries in second place (44\%). The power of employer brands and the waning importance of corporate responsibility. Millennials are attracted to employer brands that they admire as consumers. In 2008 88\% were looking for employers with CSR values that matched their own, and $86 \%$ would consider leaving an employer whose values no longer met their expectations. Fast forward three years and just over half are attracted to employers because of their CSR position and only 56\% would consider leaving an employer that didn't have the values they expected. Millennials are also turned off by some entire sectors $-30 \%$ of Swiss. 
As society we continue to evolve and things are always improving. Think back to the 1960s, 1970s, 1980 s, and so on. We have better technology, a better understanding of science, amazing access to communication and media. Each generation has made improvements. Millennials are different to the Gen Xers and baby boomers mainly in that they have grown up at a time where nearly every aspect of their lives has been infiltrated by technology. This has not only shaped their needs and wants from an employment perspective, but also it alters the management style they will have as leaders themselves.

Millennials value what are considered soft principles when it comes to leadership. These include areas such as wellbeing and employee development. Only one in ten millennials felt that effective leaders focused on the bottom line alone. Qualities such as the ability to inspire, vision, the ability to make decisions, and passion were all earmarked as vital characteristic for a strong leader. Communication skills and relationshipbuilding are often highlighted as the most important skills, with more than half of millennials seeing these as essential (58\% and 55\% respectively). They also noted these as their core strengths, while industry knowledge (43\%) and technical expertise (41\%) were seen as less important for a leader.

The majority of millennials want to be transformational leaders who disrupt the status quo and inspire their team. The nature of leadership is evolving and the more traditional hierarchy with a leader imposing rigid control has fallen in popularity with collaboration and innovation being the key priorities in the minds of millennial leaders.

\section{I.I Following Graph showing leadership opportunities perceived by millennials.}

Leadership Opportunities Perceived by Millennials

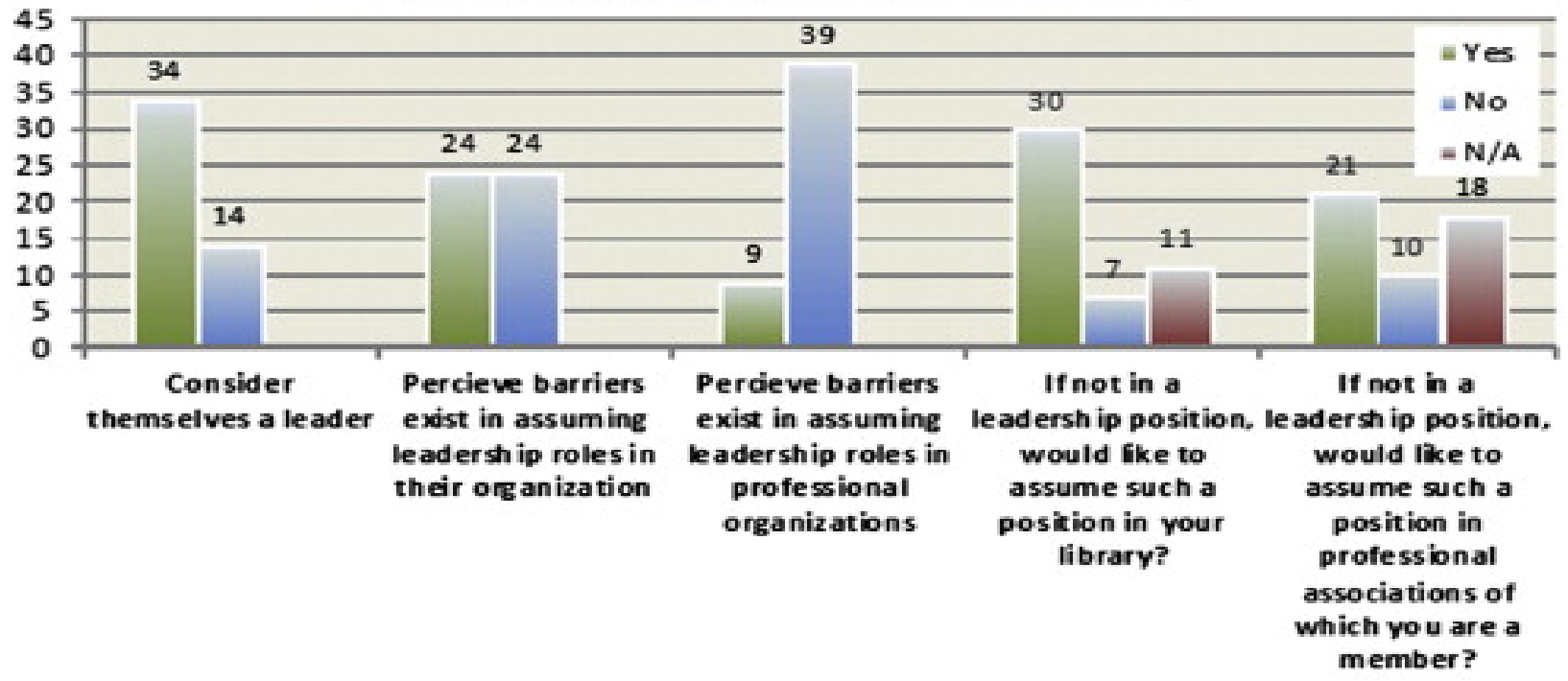

https://doi.org/10.1016/j.acalib.2013.09.006: science Direct.

\section{I.II Graph shows why millennial want to be leader.}

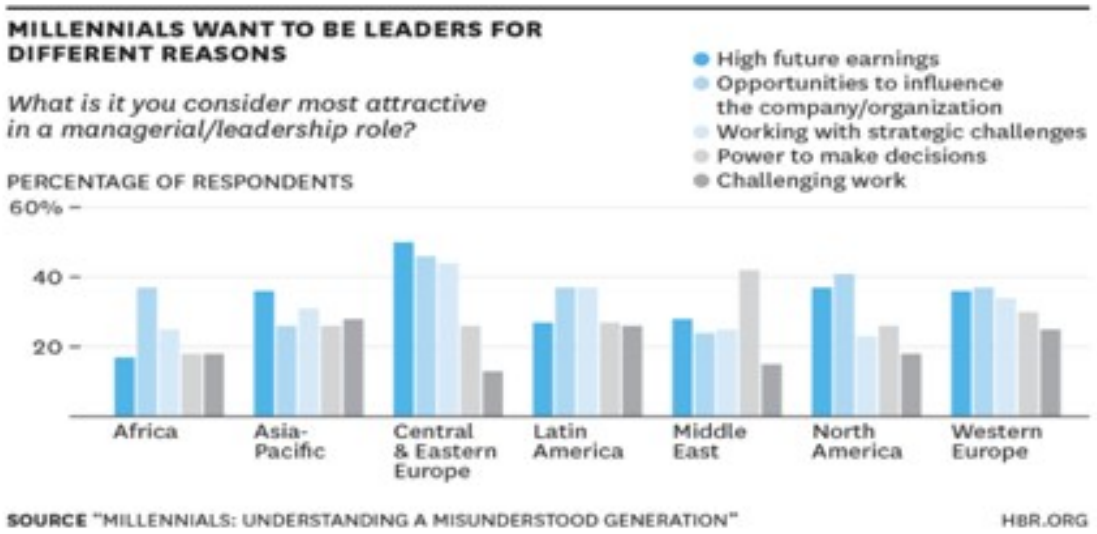




\section{I.III Graph shows kinds of Managers millennials}

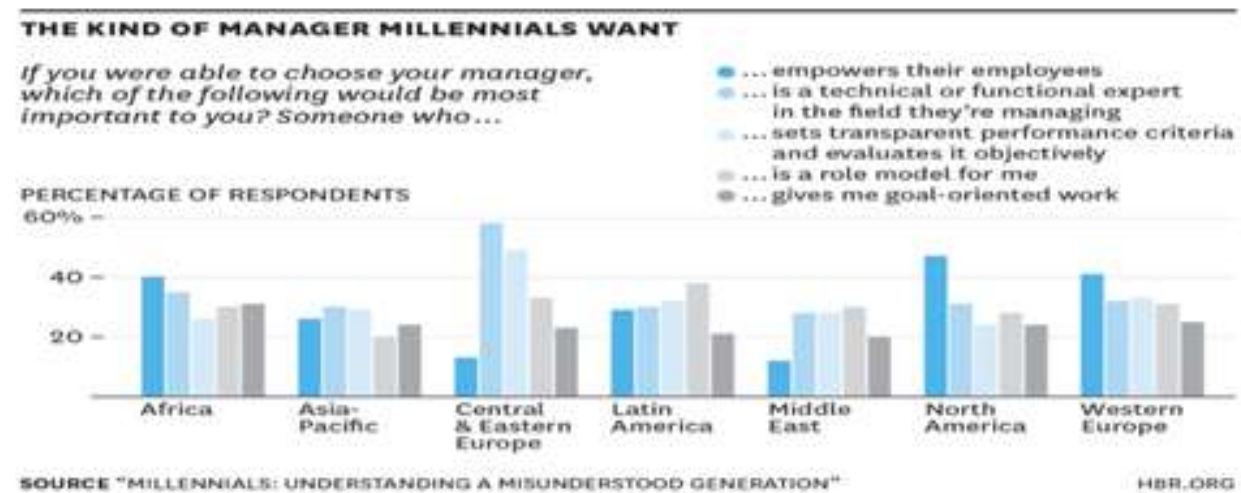

\section{CONCLUSIONS:}

Millennials are living and breathing the change in our society, from analogue to digital and from local to global. As Millennials take on more leadership positions, not only there be a shift in leadership trends, there will be a shift in the needs of leadership development as well. Millennials are a confident generation and employers have a challenge on their hands a positive challenge. This challenge presents employers with an opportunity to develop and adapt their work environments to meet the requirements of this generation. Attraction and retention of talent is the biggest challenge facing employers in the current market and tapping the millennial employee resource pool is critical. It is important to stay ahead of the curve. Organisations need to be aware of any unconscious bias against this new generation because they have a different approach to work and a different method of achieving their goals. Millennials have a strong drive to do good. A high number of millennials see giving back to society and being civilly engaged amongst their highest priorities. Millennials themselves might not be so different from other people, but the change (and pace of change) they represent is significant. Millennials are an anchor for this change. Millennials have shaped and consumed innovations and they will soon be the most dominant generation in the workforce.. They are the first generation of digital natives, and their affinity for technology helps shape how they consume.

\section{SUGGESTIONS}

1. Leaders need to take greater risks that have bigger consequences than they are comfortable with.
2. They need to stay positive when others are criticizing them.

\section{REFERENCES:}

1) Jim Russell September $(28,2016)$ Millennials: the next generation of leaders

2) Patrick Willer, 26 Jun 2015 What can we learn from Millennials SAP Community Network

3) Charla Huber April 8, 2018 the millennials are our future leaders Charla Huber/ Times Colonist

4) Retool-recruiting-to-attract-millennials.aspx.../( Mar 21，2017 ） https://www.shrm.org/hrtoday/news/hr

5) Deloitte (Jul12,2017) /global//articles/millennial survey https://www.deloitte.com

6) Jeff-haden (10 March, 2018 ) Managing Millennial and the Future of Leadership (https://www.inc.com/ /managing-millenials-howto-lead-connect-and-engage-millenialemployees.html

7) Why-the-most-successful-businesses-havestrong-leaders.(Values/2017/04/) https://ww w.weforum.org/agenda/

8) Millennial-leaders-need-to-avoid mistakes ( Jul 12, 2017) https://www.forbes.com/sites/

http://fortune.com/best-companies 